\title{
Erratum to: On the Class of Potentials with Trivial Monodromy Khabir Ishkin ${ }^{1 *}$ and Rustem Marvanov ${ }^{\text {*** }}$ \\ (Submitted by A. B. Muravnik) \\ ${ }^{1}$ Bashkir State University, Ufa, 450076 Russia \\ Received October 15, 2021; revised October 15, 2021; accepted October 15, 2021
}

DOI: $10.1134 / \mathrm{S} 1995080221120416$

Section Funding, the last sentence should read as follows:

Second author's research was supported by Russian Foundation for Basic Research (grant no. 20-31-90099).

The original article can be found online at https://doi.org/10.1134/S199508022106010X

\footnotetext{
*E-mail: ishkin62@mail.ru

***mail: rsmar1v@gmail.com
} 